\title{
Management of acute closed-angle glaucoma with miotics and timolol
}

\author{
P. J. AIRAKSINEN, K. M. SAARI, T. J. TIAINEN, AND E.-A. T. JAANiO \\ From the Department of Ophthalmology, University of Oulu, Oulu, and the Institute of Clinical Sciences, \\ University of Tampere, Tampere, Finland
}

SUMMARY The hypotensive effect of intramuscular or intravenous acetazolamide with frequent instillation of $2 \%$ or $4 \%$ pilocarpine in polyvinyl alcohol, or with single drops of pilocarpine in polyvinyl alcohol or oily vehicles, and the hypotensive effect of topical timolol alone and together with pilocarpine was investigated in the treatment of acute closed-angle glaucoma in 75 patients (81 eyes). The results showed that there was no marked difference in the hypotensive effect whether pilocarpine was used frequently or in a single dose, in different concentrations, or in different vehicles after acetazolamide. Topical timolol alone was not effective enough to control the intraocular pressure in acute closed-angle glaucoma, but a good hypotensive effect was seen when topical timolol was followed by pilocarpine. It is concluded that 1 drop of pilocarpine 3 hours after intravenous or intramuscular acetazolamide or after topical timolol may be sufficient to terminate an acute attack. Topical timolol may serve as a valuable alternative when systemic medication is contraindicated.

The initial treatment of acute closed-angle glaucoma (CAG) is directed towards lowering intraocular pressure (IOP) by medical means to avoid operating upon a congested eye. This is usually achieved with carbonic anhydrase inhibitors, osmotic agents, and pilocarpine. Miotics may be used with frequent instillation, or once 3 or 4 hours after intravenous acetazolamide (Ganias and Mapstone, 1975). Pilocarpine is usually administered in polyvinyl alcohol (PVA) or methyl cellulose vehicles. Application of pilocarpine in oil produces an increased hypotensive effect in open-angle glaucoma (Saari et al., 1978b). The effect of pilocarpine in oily drops has not been studied in CAG. A beneficial effect from a pilocarpine-soaked hydrophilic lens in the management of CAG has been reported (Hillman, 1974; Hillman et al., 1975).

A new beta-adrenergic blocking agent, timolol maleate, lowers the IOP effectively in primary open-angle glaucoma (Zimmerman and Kaufman, 1977; Boger et al., 1978; Airaksinen, 1979) and in secondary glaucoma (Saari et al., 1978a) but not in capsular glaucoma (Kerty and Hørven, 1978; Airaksinen, 1979). It reduces IOP by suppressing

Correspondence to Dr K. M. Saari, Institute of Clinical Sciences, University of Tampere, Teiskontie 35, SF-33520 Tampere 52, Finland. the formation of the aqueous humour (Zimmerman et al., 1977). Goethals and Missotten (1977) reported 2 patients with CAG who were treated with topical timolol after maximal acetazolamide and pilocarpine therapy. There are no other reports on the hypotensive effect of timolol in CAG.

In this study we examined the hypotensive effect of acetazolamide with pilocarpine, which was used in different concentrations and vehicles and with different instillation frequencies, and of topical timolol alone and together with pilocarpine.

\section{Material and methods}

Seventy-five patients (81 eyes) with CAG, 13 males and 62 females, age range 33 to 85 (mean 62) years, were included in the study. The patients were treated in one of the following 7 ways: (1) Intramuscular acetazolamide $500 \mathrm{mg}$, and $2 \%$ pilocarpine hydrochloride solution in $1.4 \%$ PVA instilled every $15 \mathrm{~min}$ for 2 hours and then every hour (Table 1, cases 1-26, 28 eyes with CAG). Together with systemic acetazolamide, glycerol was given perorally to 14 patients (Table 1, cases 13-26). (2) Intramuscular acetazolamide $500 \mathrm{mg}$, and $4 \%$ pilocarpine hydrochloride in $1.4 \%$ PVA instilled every $15 \mathrm{~min}$ for 2 hours and then every hour (Table 2, cases 27-50, 25 eyes). (3) Intramuscular acetazolamide $500 \mathrm{mg}$, 
Table 1 Hypotensive effect of acetazolamide and $2 \%$ pilocarpine (group 1) in CAG

\begin{tabular}{|c|c|c|c|c|c|c|}
\hline Case & Age & Sex & $\begin{array}{l}\text { Duration } \\
\text { (days) }\end{array}$ & $\begin{array}{l}\text { Initial } \\
\operatorname{IOP}(\mathrm{mmHg})\end{array}$ & $\begin{array}{l}\text { Final } \\
\text { IOP }(m m H g)\end{array}$ & $\begin{array}{l}\text { Time } \\
\text { (h) }\end{array}$ \\
\hline 1 & 77 & $\mathbf{F}$ & 1 & 84 & 21 & 5 \\
\hline 2 & 61 & $\mathbf{F}$ & 1 & 84 & 16 & 8 \\
\hline 3 & 70 & $\mathbf{F}$ & 1 & 70 & 15 & 5 \\
\hline 4 & 58 & $\mathbf{M}$ & 5 & 56 & 16 & 5 \\
\hline 5 & 85 & $F$ & 7 & 70 & 21 & 6 \\
\hline 6 & 73 & $\mathbf{F}$ & 1 & 44 & 16 & 6 \\
\hline 7 & 41 & $\mathbf{F}$ & 2 & 52 & 18 & 1 \\
\hline 8 & 76 & $\mathbf{F}$ & 1 & 70 & 10 & 5 \\
\hline 9 & 55 & $\mathbf{F}$ & 1 & 50 & 17 & 2 \\
\hline 10 & 64 & $F$ & 1 & 62 & 16 & 3 \\
\hline 11 & 49 & $\mathrm{~F}$ & 1 & 50 & 19 & 2 \\
\hline 12 & 55 & $\mathbf{M}$ & 7 & 70 & 18 & 4 \\
\hline 13 & 63 & $\mathbf{F}$ & 1 & 80 & 12 & 5 \\
\hline 14 & 74 & $\mathbf{M}$ & 7 & 70 & 20 & 6 \\
\hline 15 & 68 & F & 1 & 80 & 64 & 8 \\
\hline 16 & 61 & $\mathbf{F}$ & 4 & 54 & 18 & 3 \\
\hline 17 & 69 & F & 3 & 76 & 13 & 3 \\
\hline 18 & 46 & $\mathrm{~F}$ & 1 & 70 & 29 & $3^{*}$ \\
\hline 19 & 40 & $\mathbf{M}$ & 1 & 58 & 10 & 8 \\
\hline $20 \mathrm{R}$ & 53 & $\mathbf{M}$ & 1 & 65 & 11 & 2 \\
\hline $\mathbf{L}$ & 53 & $\mathbf{M}$ & 1 & 65 & 11 & 2 \\
\hline 21 & 45 & $F$ & 1 & 54 & 54 & 9 \\
\hline 22 & 60 & $F$ & 1 & 64 & 12 & 6 \\
\hline $23 \mathbf{R}$ & 47 & $F$ & 1 & 50 & 11 & 2 \\
\hline $\mathbf{L}$ & 47 & $\mathbf{F}$ & 1 & 69 & 11 & 2 \\
\hline 24 & 62 & $F$ & 1 & 70 & 16 & 2 \\
\hline 25 & 46 & $\mathrm{~F}$ & 1 & 70 & 21 & 7 \\
\hline 26 & 62 & $F$ & 1 & 62 & 55 & 10 \\
\hline
\end{tabular}

* Operated at 3 hours.

and $2 \%$ pilocarpine in a castor oil vehicle repeated once after 2 hours (Table 3, cases 51-61, 12 eyes). Four patients (Table 3, cases 56-59) received together with acetazolamide intravenous mannitol infusion and 2 patients (Table 3 , cases 60-61) glycerol perorally. (4) Two drops of $0.5 \%$ timolol within 1 hour (Table 4, cases 62-68,7 eyes). (5) Two drops of $0.5 \%$ timolol within 1 hour and 3 hours later 1 drop of $2 \%$ pilocarpine (Table 5 , cases $69-73$, 6 eyes with CAG). (6) A 59-year-old woman (case 74) with a duration of symptoms for 2 weeks and with initial IOP of $80 \mathrm{mmHg}$ in the right eye and 76 $\mathrm{mmHg}$ in the left was treated with intravenous acetazolamide $250 \mathrm{mg}$ followed by $4 \%$ pilocarpine in PVA every 15 min for 2 hours into the right eye; a hydrophilic contact lens presoaked in $1 \%$ pilocarpine was applied onto the left eye. (7) A 78-yearold woman (case 75) with duration of symptoms for one day had initial of IOP $76 \mathrm{mmHg}$ in the right eye. She was treated with intravenous acetazolamide
$500 \mathrm{mg}$ followed by 1 drop of $4 \%$ pilocarpine in PVA 3 hours later.

The treatment was considered a failure if after 8 hours IOP was greater than $21 \mathrm{mmHg}$.

\section{Results}

The results for the treatment groups are given in Tables 1-5. The duration indicates the time between onset of acute symptoms and start of therapy. Initial IOP was measured before the treatment began. Final IOP was the lowest recording at the time stated after starting treatment.

Group 1 had 3 obvious failures (cases 15, 21, and 26) and 1 patient (case 18) was operated on at 3 hours when the IOP was $29 \mathrm{mmHg}$; all these patients had received glycerol perorally together with intramuscular acetazolamide. Group 2 had 3 failures (cases 41, 43, and 49); in case 43 the IOP was $26 \mathrm{mmHg}$ at 8 hours and 9 hours later $16 \mathrm{mmHg}$. Group 3 had 3 failures; 1 of these (case 56) had received mannitol together with acetazolamide.

Group 4 had 4 failures (cases 64 and 66-68). In case 66 the IOP was $28 \mathrm{mmHg}$ at 8 hours and

Table 2 Hypotensive effect of acetazolamide and $4 \%$ pilocarpine (group 2) in CAG

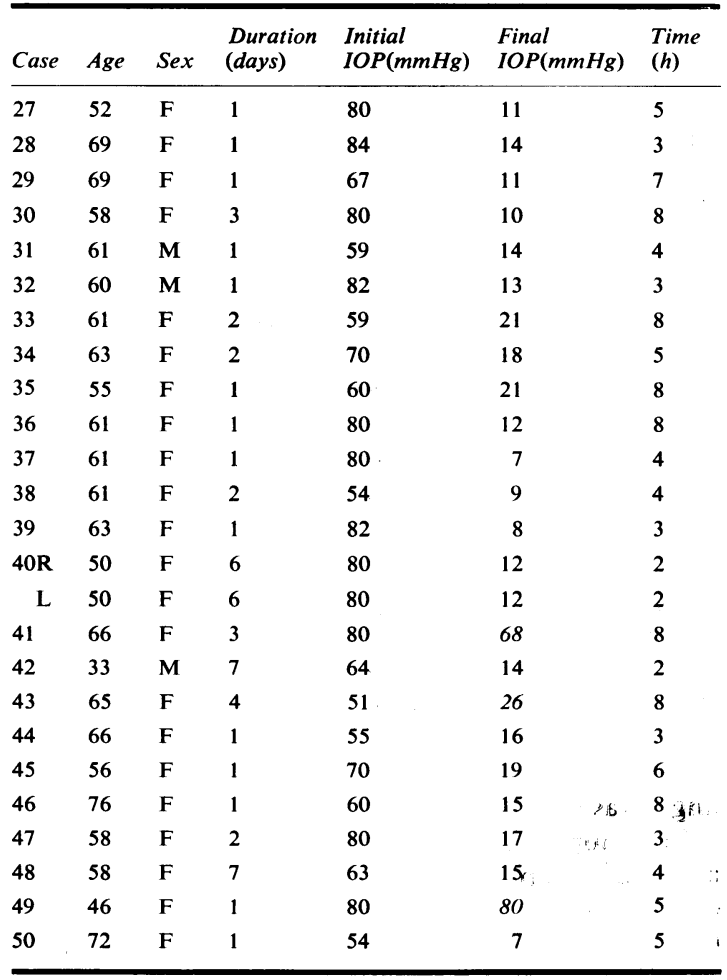


Table 3 Hypotensive effect of acetazolamide and oily drops of $2 \%$ pilocarpine (group 3) in CAG

\begin{tabular}{cllllll}
\hline Case & Age & Sex & $\begin{array}{l}\text { Duration } \\
(\text { days })\end{array}$ & $\begin{array}{l}\text { Initial } \\
\text { IOP( } \mathrm{mmHg})\end{array}$ & $\begin{array}{l}\text { Final } \\
\text { IOP }(\mathrm{mmHg})\end{array}$ & $\begin{array}{l}\text { Time } \\
(\boldsymbol{h})\end{array}$ \\
\hline 51 & 61 & F & 3 & 56 & 20 & 2 \\
52 & 80 & F & 1 & 80 & 69 & 4 \\
$53 \mathrm{R}$ & 57 & F & 1 & 80 & 14 & 2 \\
L & 57 & F & 1 & 54 & 14 & 2 \\
54 & 64 & F & 1 & 59 & 20 & 8 \\
55 & 76 & F & 1 & 82 & 40 & 8 \\
56 & 76 & F & 1 & 80 & 40 & 8 \\
57 & 69 & F & 7 & 75 & 11 & 6 \\
58 & 49 & F & 1 & 70 & 13 & 2 \\
59 & 55 & M & 2 & 56 & 16 & 2 \\
60 & 72 & F & 2 & 52 & 10 & 3 \\
61 & 49 & M & 2 & 72 & 21 & 8 \\
\hline
\end{tabular}

Table 4 Hypotensive effect of timolol (group 4) in CAG

\begin{tabular}{lllllll}
\hline Case & Age & Sex & $\begin{array}{l}\text { Duration } \\
(\text { days })\end{array}$ & $\begin{array}{l}\text { Initial } \\
\text { IOP }(\mathrm{mmHg})\end{array}$ & $\begin{array}{l}\text { Final } \\
\text { IOP }(\mathrm{mmHg})\end{array}$ & $\begin{array}{l}\text { Time } \\
(\mathrm{h})\end{array}$ \\
\hline 62 & 54 & M & 1 & 50 & 18 & 4 \\
63 & 58 & M & 2 & 59 & 18 & 1 \\
64 & 79 & F & 1 & 60 & 36 & 8 \\
65 & 66 & F & 1 & 56 & 21 & 8 \\
66 & 53 & M & 3 & 65 & 28 & 8 \\
67 & 63 & F & 5 & 60 & 38 & 4 \\
68 & 58 & F & 1 & 68 & 80 & 3 \\
\hline
\end{tabular}

Table 5 Hypotensive effect of timolol and $2 \%$ pilocarpine (group 5) in CAG

\begin{tabular}{cccccccc}
\hline Case & Age & Sex & $\begin{array}{l}\text { Duration } \\
(\text { days })\end{array}$ & $\begin{array}{l}\text { Initial } \\
\text { IOP } \\
(\mathrm{mmHg})\end{array}$ & $\begin{array}{l}\text { IOP } \\
\text { at } 3 \mathrm{~h} \\
(\mathrm{mmHg})\end{array}$ & $\begin{array}{l}\text { Final } \\
\text { IOP } \\
(\mathrm{mmHg})\end{array}$ & $\begin{array}{l}\text { Time } \\
(\mathrm{h})\end{array}$ \\
\hline $69 \mathrm{R}$ & 81 & F & 7 & 69 & 43 & 26 & 8 \\
L & 81 & F & 7 & 69 & 37 & 21 & 8 \\
70 & 77 & F & 1 & 59 & 55 & 26 & 8 \\
71 & 63 & F & 1 & 70 & 55 & 17 & 4 \\
72 & 78 & F & 2 & 62 & 46 & 42 & 8 \\
73 & 60 & F & 20 & 54 & 42 & 21 & 8 \\
\hline
\end{tabular}

6 hours later $20 \mathrm{mmHg}$. In case 67 the IOP was $38 \mathrm{mmHg}$ at 4 hours and the patient was given $500 \mathrm{mg}$ acetazolamide perorally; 8 hours later the IOP was $18 \mathrm{mmHg}$. A good hypotensive effect of timolol was seen in cases 62,63 and 65 ; in case 65 gonioscopic examination showed that the chamber angle was still occluded.

In group 5 all cases showed decrease of IOP 3 hours after timolol (Table 5) and subsequent pilocarpine caused reduction to normal of IOP in 3 eyes (cases 69 left eye, 71, and 73). Gonioscopic examina- tion was performed for case 73 , which revealed an open chamber angle. In case 69 the reduction of IOP was considered sufficient also in the right eye, and both eyes were successfully operated on. In case 70 the IOP was $26 \mathrm{mmHg}$ and in case 72 it was 42 $\mathrm{mmHg}$ at 8 hours; in both cases the IOP was 15 $\mathrm{mmHg} 12$ hours later.

The 59-year-old woman (case 74 ) with bilateral CAG had a final IOP of $12 \mathrm{mmHg}$ at 2 hours in both the right eye treated with intensive instillation of $4 \%$ pilocarpine and the left eye treated with a pilocarpine presoaked hydrophilic contact lens. In the right eye of the 78-year-old woman (case 75) treated with 1 drop of $4 \%$ pilocarpine 3 hours after acetazolamide the final IOP was $16 \mathrm{mmHg}$ at 8 hours after starting the treatment.

\section{Discussion}

The results indicate that frequent instillation of $4 \%$ pilocarpine (Table 2) does not have a greater hypotensive effect in CAG than $2 \%$ pilocarpine (Table 1 ). Therefore $4 \%$ pilocarpine should not be used, because excessive use of pilocarpine may produce toxic side effects (Epstein and Kaufman, 1965). To diminish the frequency of instillations and the total dose of pilocarpine in the treatment of CAG the use of a pilocarpıne-soaked hydrophilic contact lens has been suggested. This method is as effective as intensive medication with $4 \%$ pilocarpine (Hillman, 1974); we could observe this in 1 patient.

The instillation frequency may also be reduced by oily drops of pilocarpine, which have a strong and long-lasting miotic effect (Borgmann and Wurster, 1973; Saari et al., 1978c; Smith et al., 1978) and may provide a more conventional and less expensive alternative than a pilocarpine-soaked hydrophilic contact lens in the treatment of CAG. In this study 1 or 2 oily drops of pilocarpine administered after intramuscular acetazolamide had a good hypotensive effect in 9 of 12 eyes. Ganias and Mapstone (1975) observed that 1 drop of pilocarpine 3 hours after intravenous acetazolamide suffices to stop the attack. A similar observation was made in this study when pilocarpine-PVA drops were used.

In CAG miotics will not cause the ischaemic sphincter to react until the IOP is lowered by other means (Rutkowski and Thompson, 1972). In this study intramuscular or intravenous acetazolamide followed by pilocarpine had a good hypotensive effect in CAG, but additionally given peroral glycerol did not improve the results (Table 1, cases 13-26).

Topical timolol maleate reduces IOP by suppressing aqueous humour production nearly as effectively as systemic carbonic anhydrase inhibitors (Coakes and Brubaker, 1978), but in contrast to these and 
osmotic agents topical timolol has no appreciable side effects. In this study 2 drops of timolol had a good hypotensive effect in 3 cases with $\mathrm{CAG}$, and topical timolol followed 3 hours later by pilocarpine reduced the IOP to normal levels in all cases during an extended observation period.

On the basis of the results of this study and of an earlier report (Ganias and Mapstone, 1975) it is sufficient to treat patients with $C A G$ with intramuscular or intravenous acetazolamide $500 \mathrm{mg}$ and 3 hours later by a single drop of pilocarpine. When the patient cannot be treated with systemic medication, it seems appropriate to substitute topical timolol for acetazolamide to reduce the IOP to a level where the sphincter starts to react and then give pilocarpine to open the occluded chamber angle.

\section{References}

Airaksinen, P. J. (1979). The long-term hypotensive effect of timolol maleate compared with the effect of pilocarpine in simple and cajsular glaucoma. Acta Ophthalmologica, 57, 425-434.

Boger, W. P. III, Steinert, R. F., Puliafito, C. A., and Pavan-Langston, D. (1978). Clinical trial comparing timolol ophthalmic solution to pilocarpine in open-angle glaucoma. American Journal of Ophthalmology, 86, 8-18.

Borgmann, H., and Wurster, W. (1973). Der Einfluss unterschiedlicher Konzentrationen und Vehikel auf die Pilocarpin-Miosis. II. Unterschiedliche Vehikel. Klinische Monatsblätter für Augenheilkunde, 163, 51-56.

Coakes, R. L., and Brubaker, R. F. (1978). The mechanism of timolol in lowering intraocular pressure. Archives of Ophthalmology, 96, 2045-2048.
Epstein, E., and Kaufman, I. (1965). Systemic pilocarpine toxicity from overdosage. American Journal of Ophthalmology, 59, 109-110.

Ganias, F., and Mapstone, R. (1975). Miotics in closedangle glaucoma. British Journal of Ophthalmology, 59, 205-206.

Goethals, M., and Missotten, L. (1977). Long term trial of timolol in different forms of glaucoma. Bulletin de la Société Belge D'Ophthalmologie, 179, 95-101.

Hillman, J. S. (1974). Management of acute glaucoma with pilocarpine-soaked hydrophilic lens. British Journal of Ophthalmology, 58, 674-679.

Hillman, J. S., Marsters, J. B., and Broad, A. (1975). Pilocarpine delivery by hydrophilic lens in the management of acute glaucoma. Transactions of the Ophthalmological Societies of the United Kingdom, 95, 79-84.

Kerty, E., and Hørven, I. (1978). Glaucoma treatment with timolol. Acta Ophthalmologica, 56, 705-714.

Rutkowski, P. C., and Thompson, H. S. (1972). Mydriasis and increased intraocular pressure. Archives of Ophthalmology, 87, 21-24.

Saari, K. M., Airaksinen, P. J., and Jaanio, E.-A. T. (1978a). Hypotensive effect of timolol on secondary glaucoma in chronic uveitis. Lancet, 1, 442.

Saari, M., Koskela, P., and Masar, S.-E. (1978b). Effect of vehicle on pilocarpine-induced ocular hypotension. Acta Ophthalmologica, 56, 489-495.

Saari, M., Koskela, P., and Masar, S.-E. (1978c). Effect of vehicle on pilocarpine-induced miosis. Acta Ophthalmologica, 56, 496-503.

Smith, S. A., Smith, S. E., and Lazare, R. (1978). An increased effect of pilocarpine on the pupil by application of the drug in oil. British Journal of Ophthalmology, 62, 314 317.

Zimmerman, T. J., Harbin, R., Pett, M., and Kaufman, H. E. (1977). Timolol and facility of outflow. Investigative Ophthalmology and Visual Science, 16, 623-624.

Zimmerman, T. J., and Kaufman, H. E. (1977). Timolol, a beta-adrenergic blocking agent for the treatment of glaucoma. Archives of Ophthalmology, 95, 601-604. 